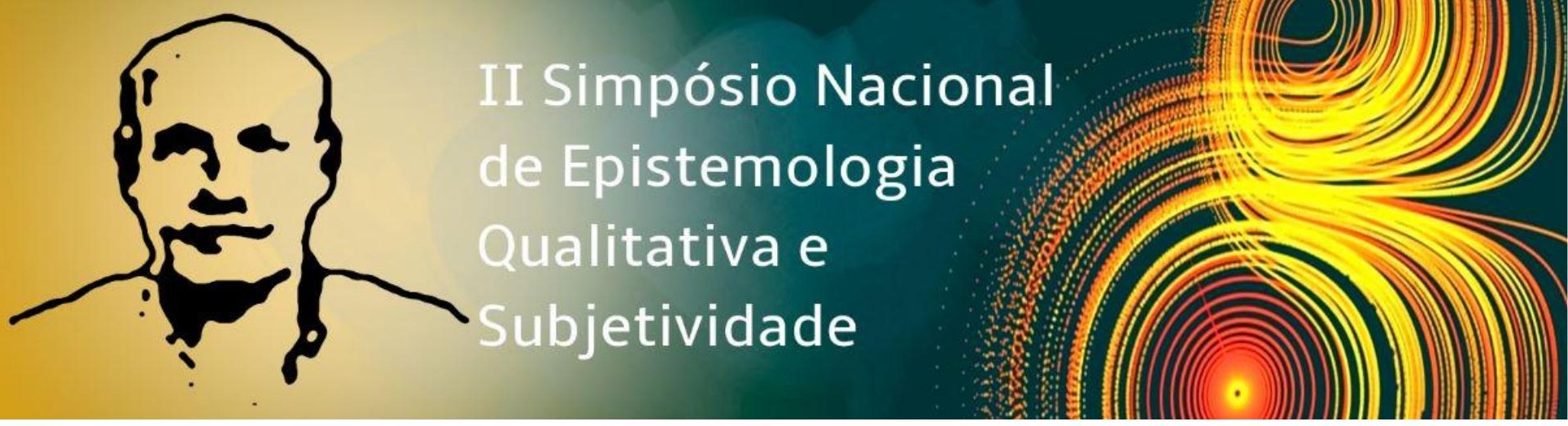

Eixo temático: Teoria da subjetividade: discussões conceituais e relações com outros referenciais teóricos

\title{
RETORNO OU DESAFIO? A NOÇÃO DE SUJEITO E DE SUA SUBJETIVIDADE NO CAMPO DAS REPRESENTAÇÕES SOCIAIS, ALGUMAS IMPLICAÇÕES
}

\author{
Andreia dos Santos Gomes Vieira, SEEDF/ UnB, andreia.pacp@gmail.com \\ Cristina Massot Madeira Coelho, UnB, cristina.madeira.coelho@gmail.com
}

\section{Resumo}

Em estudo anterior, de 2015, a ideia de rotinas pedagógicas como conhecimento construído a partir de informações compartilhadas e difundidas no campo da Educação Infantil, favoreceu a análise desta categoria pedagógica, sob a luz da Teoria das Representações Sociais, tendo como vertente metodológica a Teoria do Núcleo Central de Abric (1998). Todavia, naquele estudo, não se alcançou compreender a participação efetiva dos indivíduos na produção de sentidos que balizam as representações. Embora existissem certos níveis de generalização quanto aos elementos constituintes das rotinas pedagógicas, esses não se configuravam em sentidos homogêneos, o que nos levou a pensar sobre o lugar do indivíduo na produção de representações sociais. Este texto tem por objetivo refletir questões de ordem teórica e metodológica entre a Teoria da Subjetividade na perspectiva cultural-história de González Rey e a Teoria das Representações Sociais. Consideram-se três questões pontuais: a noção de sujeito, a dicotomia individual-social e o papel das emoções nos processos humanos. Em relação às implicações metodológicas critica-se o viés cognitivista decorrente do desenvolvimento relacionado às representações sociais. Entende-se que a mera identificação descritiva de uma representação social seja redutora da compreensão do próprio fenômeno. A pesquisa de elementos que geram tais representações, a partir da processualidade de ações e produções do próprio indivíduo, torna-se um processo decorrente da construção interpretativa que, assim, vai exigir metodologias diferenciadas, tal como a que decorre da Epistemologia Qualitativa. 


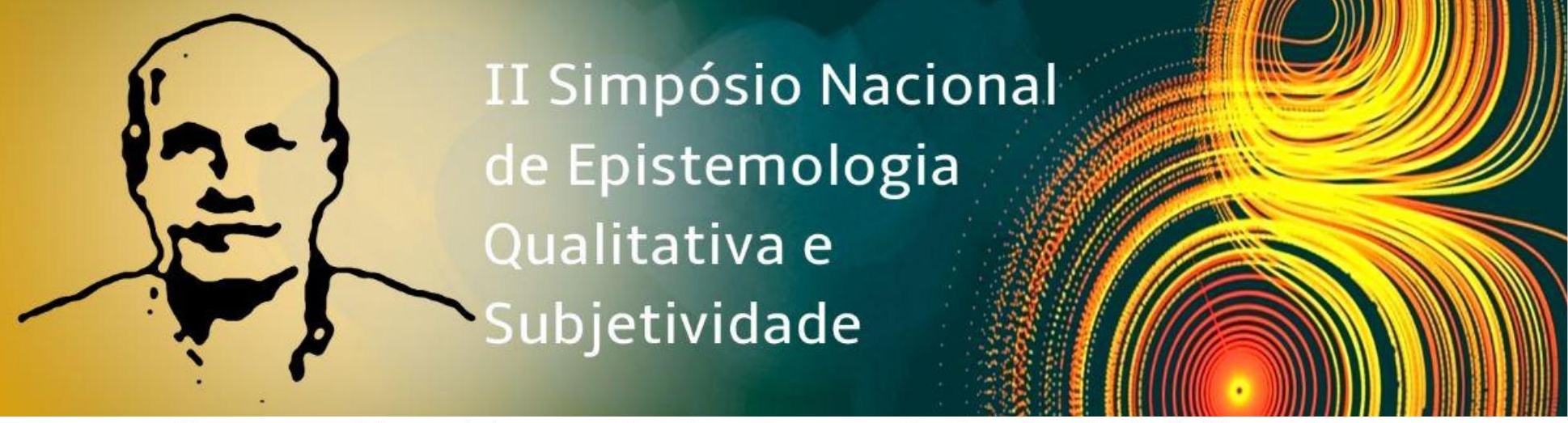

No entanto, Moscovici apesar de não negar a produção ativa do indivíduo, não a enfatiza. Gonçalves (2011) aponta que para o autor a representação social não deixa de ser uma apropriação subjetiva do mundo, embora seja sentida como uma presença objetiva da realidade. Todavia, Moscovici não conseguiu incorporar ao conjunto teórico que propôs uma solução para a articulação entre o individual e o social de modo a enfatizar e evidenciar o sujeito e sua subjetividade na produção de representações sociais.

Uma das críticas enfrentadas pela teoria é de não dar visibilidade ao indivíduo como produtor de representações sociais. O foco no social, na busca por romper com o individualismo soberano no campo da psicologia comum em sua época, pode ter contribuído para que o sujeito individual fosse desconsiderado nas pesquisas de representações sociais, contribuindo para a necessidade da emergência, assinalada por González Rey (2008) e por Jodelet (2009), do retorno da noção do sujeito aos estudos neste campo.

Pontuamos também, que sendo o objeto de estudo das representações sociais a construção do conhecimento do senso comum, o desenvolvimento da singularidade nesse processo, é mencionado, mas não explicado, como afirma Banchs (2002), ou explicitado, e o lugar do subjetivo nas representações sociais fica relegado a uma posição secundária.

González Rey (2015) pondera que embora haja uma conotação subjetiva dos conceitos de ancoragem e objetivação, pressupostos da TRS, que possibilitam o entendimento das representações sociais como base subjetiva dos atos sociais, a questão da subjetividade somente começa a ser discutida de maneira explícita neste referencial muito posteriormente.

O entendimento do autor acerca das representações como base subjetiva, pode ser ilustrado pelas palavras de Moscovici (1984): "Desde que passamos a falar sobre alguma coisa, avaliá-la e assim comunicá-la (...) então podemos representar o não usual em nosso mundo usual." (MOSCOVICI, 1984, p. 128). Interpretamos nesta explanação o movimento do indivíduo, que produz sentidos mediante a suas experiências no intuito de tornar o objeto representado familiar, que não se restringe a integração cognitiva do representado, nos indicando a produção singular do indivíduo atuando nos processos de ancoragem e objetivação.

Nesta perspectiva, inferimos que ancoragem e objetivação como processos combinatórios, construções subjetivas, vão buscar nas experiências vivenciadas, na cultura e 


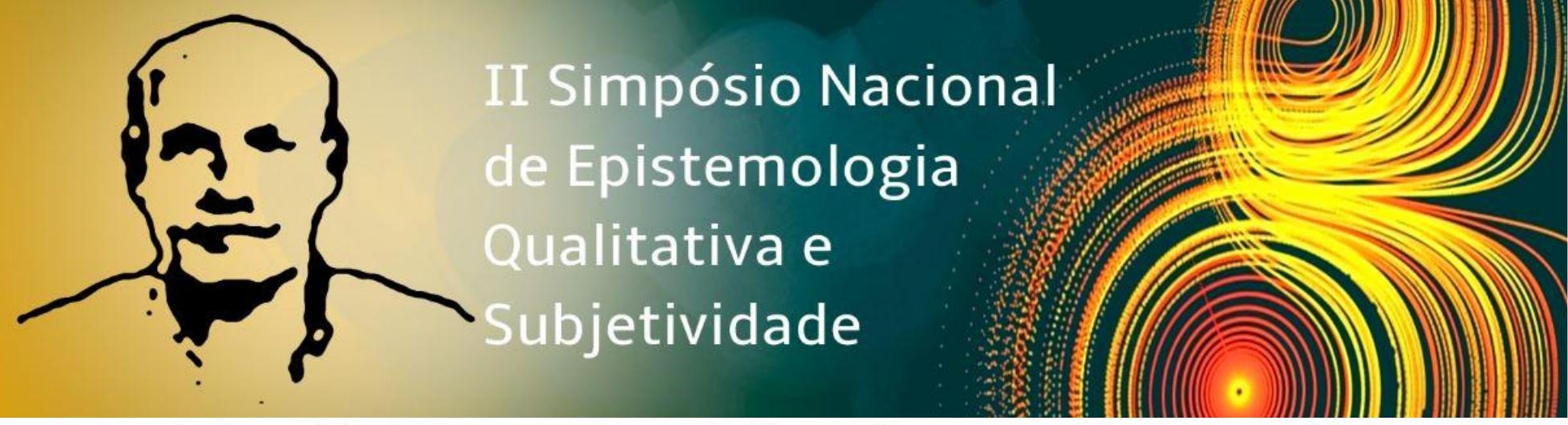

nas relações sociais elementos que possam significar o objeto representado, o que também nos permite compreendê-los, como processo de criação e, portanto, implícito de imaginação.

Para González Rey (2014) a imaginação representa a qualidade que indica o caráter subjetivo de uma produção humana, representando uma forma possível para gerar inteligibilidade sobre os significados que produzimos e que nossas práticas no mundo. Assim, compreender, ancoragem e objetivação, como processos combinatórios possibilitam a entender a produção geradora da imaginação na criação de representações sociais.

O pensamento não é simplesmente uma operação orientada para a realidade que procura uma construção lógica dessa realidade como afirma o autor. Ele se constitui uma produção subjetiva, reflexiva, que expressa a configuração subjetiva mediante a qual o indivíduo que pensa se implica no seu pensar, nas quais estão vinculados os processos imaginativos do intelecto e que são indissociáveis dos aspectos emocionais. "O emocionar-se é uma condição da atividade humana dentro do domínio da cultura, o que por sua vez se vê na gênese cultural das relações humanas." (GONZÁLEZ REY, 2003, p. 242).

Para o autor, pensar o sujeito é considerá-lo como consciente, intencional, social, cultural, emocional, sendo a emoção condição permanente na sua definição. As pessoas compartilham sentimentos que surgem e são organizados de maneira muito particular e as emoções representam um dos elementos da subjetividade humana inseparável de outras dimensões e caracterizam o indivíduo no espaço de suas relações sociais assim como na cultura.

Assim, pensar na superação da dicotomização entre o individual e o social, requer atenção à questão das emoções, que não foram organicamente integradas ao conceito de representações sociais o que podem ser explicado, segundo a perspectiva de González Rey (2003) pela ausência da ideia de sujeito individual.

Banchs (2002) aponta para a necessidade de desenvolver o papel que desempenham os processos emocionais que ocorrem especialmente nas interações face a face da vida cotidiana na construção das representações sociais, por entender que até então, as explicações a respeito da estrutura das representações sociais têm ficado em um nível muito cognitivista. A constatação da autora se articula à pauta compartilhada por Jodelet (2017) em sua explanação no Colóquio Aproximações Teóricas no Contexto da Psicologia Social, realizado no Brasil,

\section{BRASÍLIA, 22 a 25 DE OUTUBRO DE 2019 \\ CENTRO UNIVERSITÁRIO DE BRASÍLIA - UNICEUB}




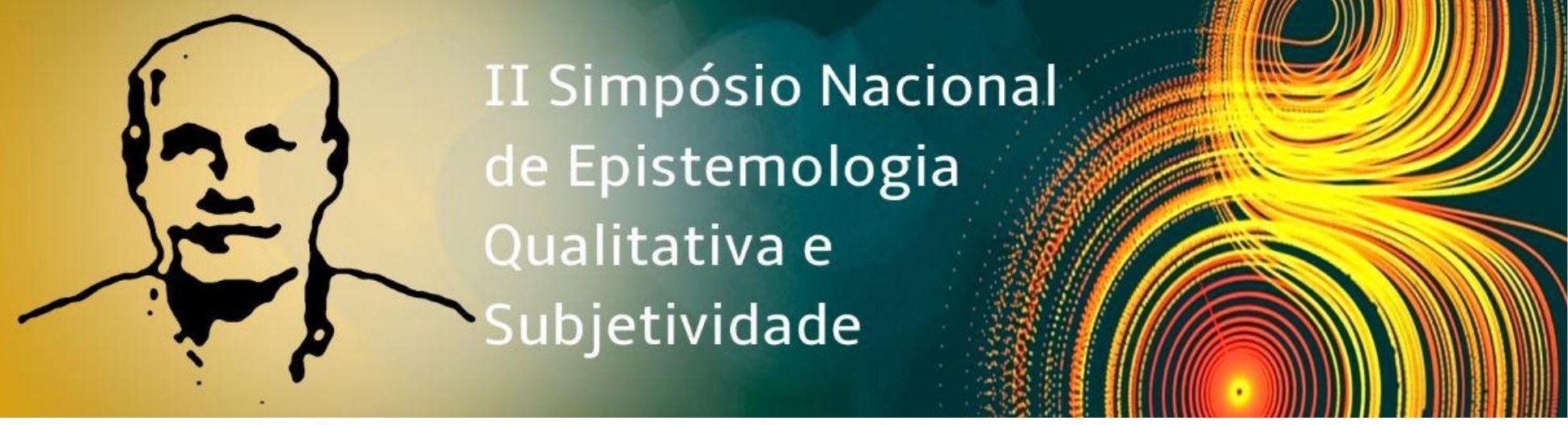

como mencionados antes, em que constata o vazio em relação ao papel desempenhado pelas emoções no processo de construção de representações sociais.

Históricas na sua essência, as representações sociais, são elaboradas na cultura e influenciam o desenvolvimento do indivíduo desde a mais tenra idade. Como fenômenos relacionais, elas implicam os indivíduos e suas complexidades, emoções, tensão, contradições, em luta para dar sentido, interpretar e construir o mundo em que eles se encontram.

Ao afirmar que pensamos com nossas bocas, Moscovici (2003), enfatiza o papel da comunicação no constructo da TRS, evidenciando que a linguagem a comunicação são parte de sua definição. Neste enfoque, as representações que são construídas nos processos de comunicação, são também recicladas e perpetuadas por meio do discurso público, cuja função é possibilitar que a comunicação seja possível entre os membros de uma comunidade.

Moscovici (2003) reconheceu o caráter gerador das representações sociais, como também, enfatizou seu caráter simbólico. Como "fenômenos simbólicos, produzidos na esfera pública" (JOVCHELOVITCH, 2000, p. 40), as representações sociais são produzidas nos encontros entre os atores sociais, em espaços formais, institucionalizados ou informais. São radicadas nas várias mediações da vida onde as pessoas reúnem-se para falar, trocar e dar sentido ao cotidiano, e nesta compreensão, não podem estar desvinculadas de processos afetivos, como aponta Jovchelovitch (2000).

Para a autora os afetos desempenham importante papel na construção de representações sociais e estão vinculados ao desenvolvimento histórico peculiar e a um conjunto de práticas que compõe o cotidiano das pessoas e deste modo, não podem estar desvinculados das práticas que ocorrem socialmente.

González Rey (2015) reflete que a integração das representações sociais dentro de uma rede social viva em que essas emergem, considerando as pessoas com sentimentos compartilhados, e de maneira muito singular, é um desafio para a TRS, e complementa, que tal proposta não pode ser concluída sem o desenvolvimento de novos conceitos que permitam o avanço da relação entre os sujeitos individuais e os "sujeitos sociais" (JOVCHELOVITCH, 1998), o que requer atenção para as questões emocionais. 


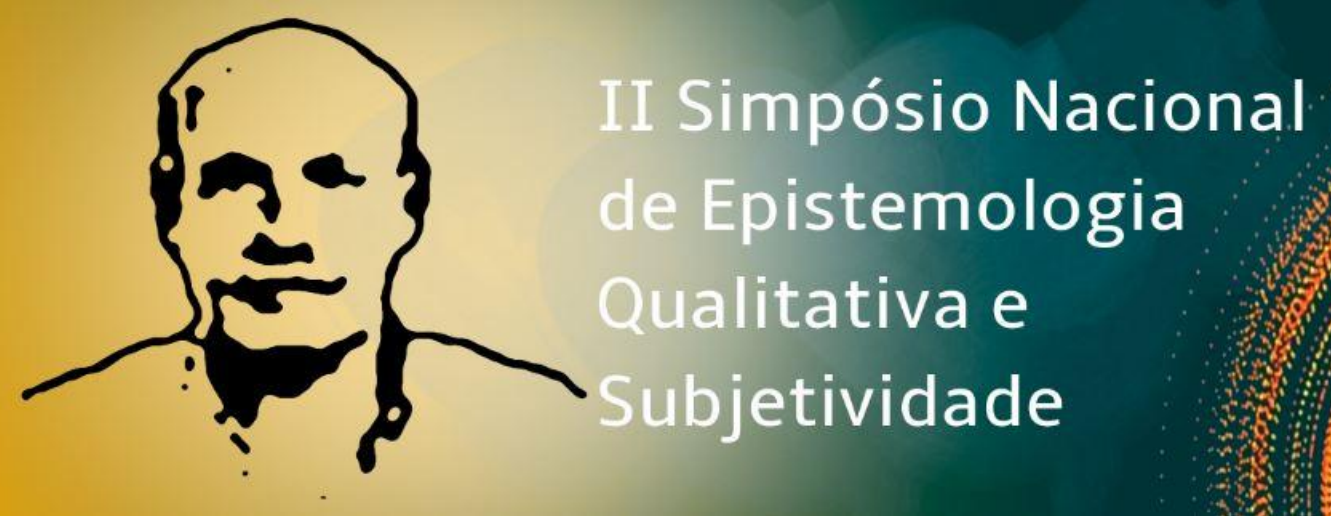

A multiplicidade de sentidos e significados que circulam na sociedade dão às representações sociais sua dimensão simbólica, mas que para González Rey (2003) também é social e subjetiva, cujas emoções são indissociáveis da produção humana e assim, inseparáveis dos processos simbólicos.

O simbólico para a TS refere-se a todos os processos que substituem, transformam, sintetizam sistemas de realidades objetivas em realidades humanas inteligíveis somente na cultura. São produções não lineares e não diretas, têm caráter singular, gerador da psique e da subjetividade, indissociáveis dos processos emocionais, intelecto, fantasia, imaginação.

Nesta vertente, as categorias sentido subjetivo e configuração subjetiva podem contribuir para na compreensão das representações sociais que ultrapasse seu caráter estritamente simbólico, podendo representar uma possibilidade de abordar as emoções presentes no cerne das representações por se constituírem inseparáveis do mundo simbólico da cultura, atravessando todas as produções simbólicas socialmente geradas e configuradas subjetivamente pelos atores que são tanto individuais quanto sociais, lacuna identificada na TRS.

González Rey (2015) indica que o caráter simbólico das representações sociais enfatizado por Moscovici em suas obras na segunda metade da década de 1970, não tem sido evidenciado nas diferentes definições teóricas que historicamente foram legitimadas como parte da tendência dentro do arcabouço da TRS. Para ele, o fato de Moscovici não ter sido claro o suficiente em suas obras sobre o que significa o caráter simbólico, podem ter contribuído para contradições que, ao longo do tempo, têm caracterizado alguns dos principais conceitos de sua teoria em linhas teóricas que abordam os estudos das representações sociais.

Moscovici (1976) também não desenvolveu uma metodologia própria para os estudos das representações. Acreditava na multiplicidade de métodos para se chegar ao conhecimento de um objeto e demonstrava resistência em apresentar uma definição imperativa acerca das representações sociais, julgando que tal feito poderia resultar em uma limitação de seu alcance conceitual. 


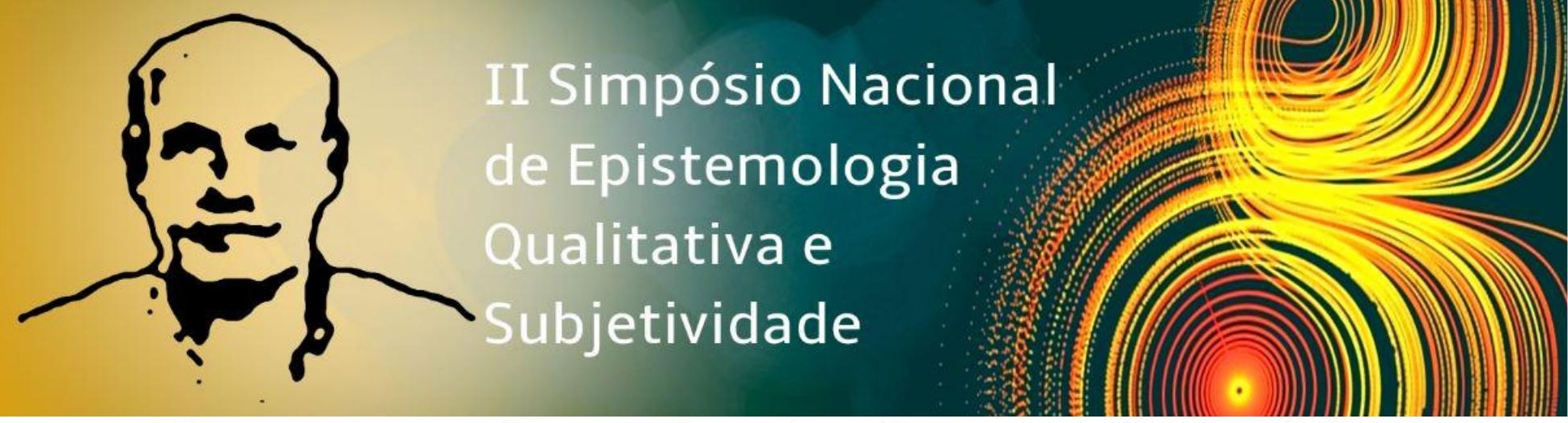

No entanto, a postura do autor recebeu muitas críticas quanto ao rigor dos métodos investigativos e as correntes e estudos que abordam a TRS e auxiliaram na difusão da teoria geraram diferentes interpretações, como chama a atenção González Rey (2015).

Entre as críticas lançadas pelo autor, encontra-se a forma como a teoria tem sido explorada, com estudos descritivos estreitos que foram realizados em nome da TRS. Segundo González Rey (2015), as descrições simples de alguns atributos comuns em relação a um dado objeto social não devem ser consideradas como representação social e a subordinação às regras do método assim como a redução da teoria a um sistema lógico-cognitivo, têm limitado o conceito de representações sociais.

O Grupo Midi, encabeçado por Abric (1998), foi o único a desenvolver uma metodologia própria no estudo das representações sociais, a proposição teórica está fundamentada sobre uma perspectiva metodológica experimental.

Os pesquisadores desta vertente estão interessados em explicitar o núcleo central, apreciar a estrutura ou a organização interna das representações sociais, em "reduzir em grande medida a parte de interpretação ou de elaboração pelo pesquisador e torna, portanto, a análise dos resultados mais fácil e mais pertinente." (ABRIC apud SÁ, p. 1996, p. 71).

A metodologia criada por Abric (1998) pode ter se constituído como uma resposta às exigências metodológicas e instrumentalistas decorrentes da legitimação científica predominante no campo das ciências sociais e humanas. Todavia, como ressalta Banchs (2002) a perspectiva estruturalista, demonstra-se mais próxima ao sociocognitivismos americano do que a proposta das representações sociais, tal como Moscovici a criou.

Jodelet (2005) reflete a racionalização das representações e problemas de ordem metodológica, apontando carência de instrumentos de análise para além do nível da simples descrição de imagens expressivas de atitudes culturais.

É reconhecido que a abordagem cognitivista evidenciou as propriedades estruturais da representação, no entanto, a dominância de modelos baseados no tratamento da informação, por exemplo, produziu e reforçou uma concepção do processo mental cortado do laço social. Por mais importante que seja essa formalização, é conduzida a negligenciar importantes aspectos da representação social. 


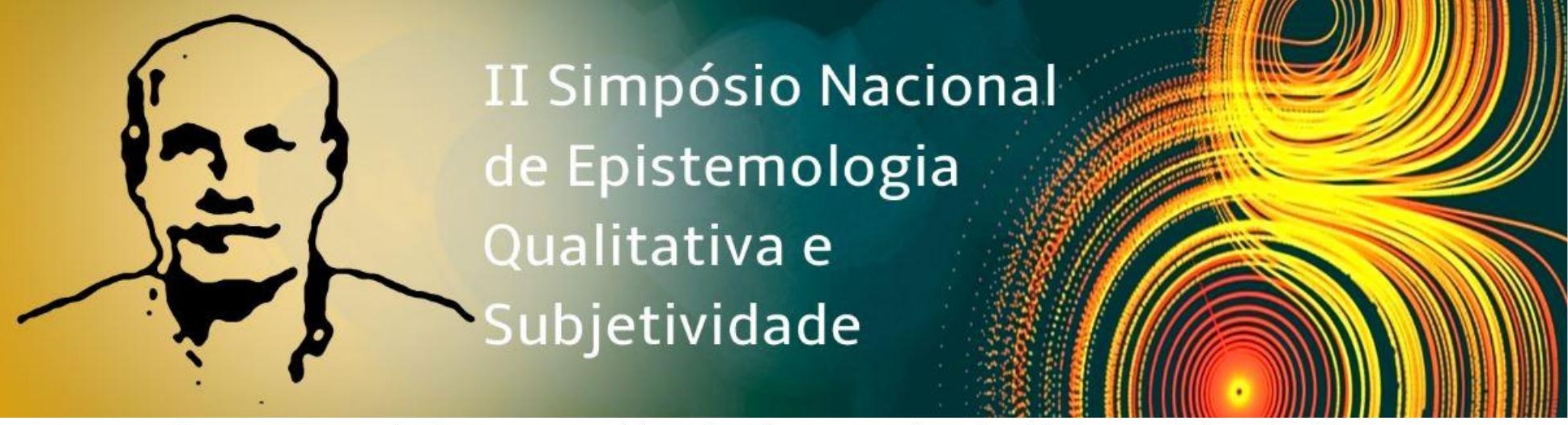

Para a autora o isolamento cognitivo, focado no que é conhecido e como é conhecido, descuida sobre aquele que sabe e como sabe. Negligencia o aspecto simbólico, exclui a expressividade da representação e sua relação com a vida afetiva e emocional, o que considera um obstáculo para pesquisas no campo das representações (JODELET, 2005).

Entendemos o papel que o trabalho de Abric (1998) tem oferecido aos estudos das representações sociais, como também o movimento que a teoria tem ganhado em seus mais de cinquenta anos. Todavia, a partir de nossa própria empreitada, observamos que somente a identificação das representações sociais não possibilitou evidenciar outros elementos que podem estar implícitos na produção das representações sociais e podem ser mobilizadores para no compartilhamento de algumas ideias e outras não. Questão que em nossa visão a explicação pode não estar somente no campo cognitivo ou serem evidenciadas somente pelo discurso.

Scoz e Mitjáns Martinez (2009), refletindo acerca da ênfase colocada na verbalização e no discurso diário em pesquisas sobre representações sociais, apontam que na comunicação estabelecida na interação podem gerar, segundo os estudos de Abric (2005), defasagens entre o que as pessoas dizem e pensam, entre o que dizem e o que fazem, o que coloca em dúvida a compreensão das representações sociais. As autoras apontam que restringir o estudo das representações sociais apenas ao que as pessoas expressam verbalmente, de forma direta e consciente, pode ocasionar que certos elementos das representações sociais fiquem omitidos ou mascarados durante a investigação, o que é então considerado, como um fragilidade do estudo baseado estritamente em verbalizações dos participantes, em instrumentos identificadores de discursos.

Na produção de representações sociais existem a interação estabelecida entre as pessoas onde ocorrem negociações, ambiguidades, reinterpretações das informações, de conceitos e significados, próprios da condição lacunar dos indivíduos em suas relações. Neste sentido, embora os estudos das representações sociais não tivessem deixado de versar sobre a relação com o sujeito enunciador e produtor das representações sociais, a partir do entendimento da triangulação entre o sujeito, o outro e o objeto, sugerido pela própria teoria, a questão do sujeito individual, ainda não culminou como objeto de uma reflexão sistemática na abordagem teórica das Representações Sociais, como enfatiza Jodelet (2017) 


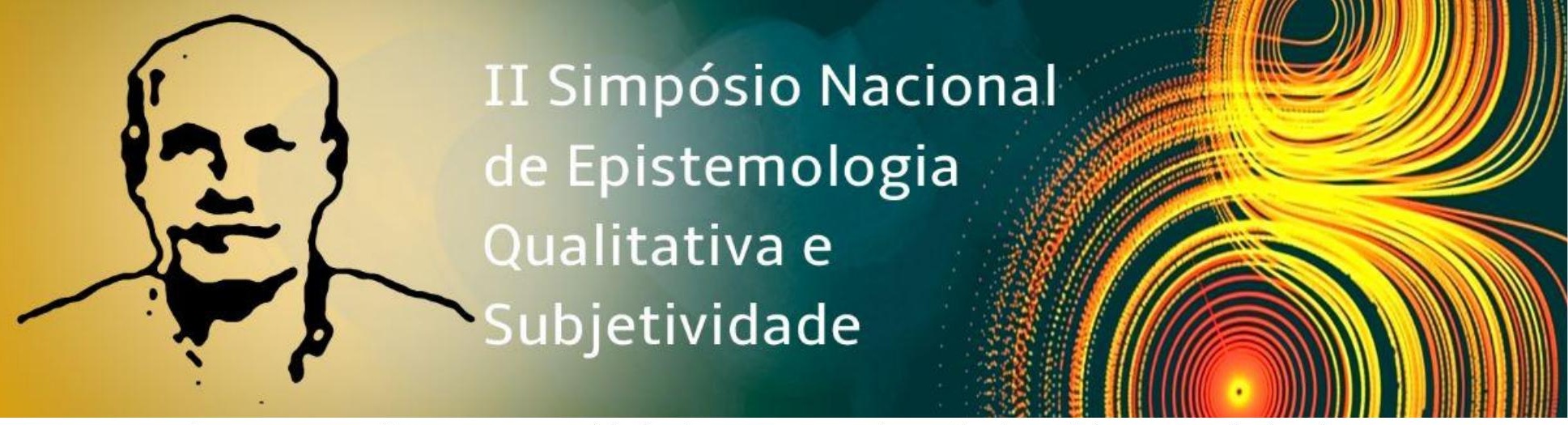

A autora ao afirmar a necessidade de um retorno à noção do sujeito capaz de inspirar uma nova abordagem da subjetividade no âmbito das representações sociais, entende que os componentes vitais do sujeito individual, de sua corporalidade e de sua vida emocional devam ter lugar no campo das representações.

Jodelet (2017) assinala que quando se trabalha com a preocupação de compreender e intervir em diversos campos da prática, forçosamente se deve pensar em questões que considerem as particularidades que afetam os indivíduos. Produto e produtor de cultura, instituindo e sendo instituído pelo social, o modo de pensar interpretar, conhecer, sentir e perceber o mundo frente a sua história e experiência de vida, é indiscutivelmente subjetivo. São estes aspectos que tornam sua existência singular ao mesmo tempo social, e orienta suas práticas, ações e comportamentos.

As representações sociais integram diferentes dimensões humanas, e nesta vertente, as abordagens que externalizam a elaboração das representações precisa articular o valor da subjetividade nesse processo.

A fim de ilustrar a constituição social do sujeito e a complexidade assumida pela proposição teórica moscoviciana que comunga, Jodelet (2017) sintetiza um esquema as "esferas ou universo de pertença das representações sociais" (p.118). Segundo a proposição autora, as representações sociais estão relacionadas a três esferas de pertencimento: a da subjetividade como capital privado que considera à experiência vivida, engajada no corpo, na sensibilidade e nas emoções ao lado dos saberes construídos; a da intersubjetividade, que remete às situações que contribuem para o estabelecimento de representações sociais elaboradas nas interação e negociação entre os sujeitos via comunicação direta; e a da transubjetividade que remonta a tudo que é comum aos membros de um mesmo coletivo, elementos reguladores da visão de mundo.

Desta forma Jodelet (2017) busca não apenas apresentar a complexa rede em que se inscrevem as representações sociais, como a potencialidade de uma perspectiva subjetivista neste campo, vislumbrando modalidade para uma ação transformadora e ainda, superar a simples descrição de estados representacionais. Considerar os fenômenos das representações sociais sem associá-los aos indivíduos que as produzem ou desvinculá-los dos locais onde eles ocorrem pode incorrer na omissão do processo dialético entre o social e o individual

\section{BRASÍLIA, 22 a 25 DE OUTUBRO DE 2019 \\ CENTRO UNIVERSITÁRIO DE BRASÍLIA - UNICEUB}




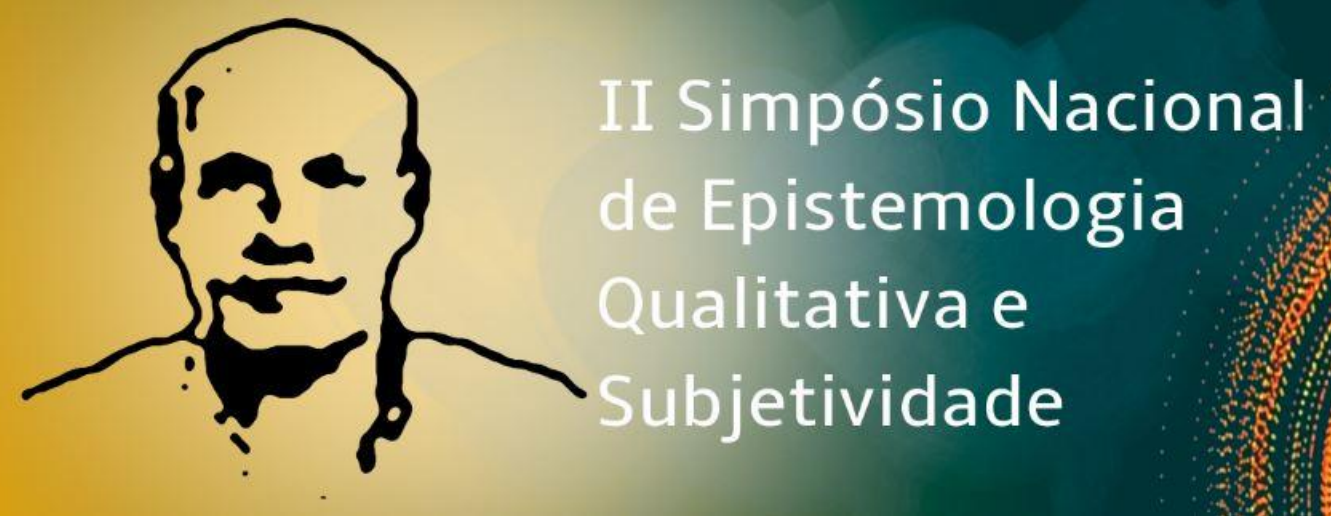

proposto pela Teoria das Representações Sociais.

Pontuamos que no modelo proposto por Jodelet (2017), podemos observar que indivíduos são ativos, afetados por diferentes aspectos cotidianos da vida, as representações sociais se encontram como produções do indivíduo que se inscreve na integração dos aspectos subjetivos, transubjetivos e intersubjetivos, na dialética com os aspectos sociais de diferentes contextos. Embora este modelo verse pelo protagonismo do sujeito produtor de representações na atuação articulada com o externo, ainda observamos uma fragmentação acerca dos aspectos individual e social.

A posição de Jodelet (2017) deixa clara a urgência que confere ao "retorno à noção do sujeito", ideia que afirma e nomeia alguns de seus estudos. Jodelet (2015) afirma ser lamentável que algumas abordagens que se utilizam da TRS venham a terceirizar processos de representações sociais e não esclarecer a parte que retorna à participação da subjetividade.

Todavia, como destaca Gonçalves (2011), o precursor da Teoria das Representações sociais não estava interessado em representações individuais, o que pode ter colaborado para críticas e questionamentos acerca da passividade dos indivíduos dentro do arcabouço teórico. Moscovici (2003) reconhece sua importância, mas não consegue colocar o sujeito na centralidade de sua abordagem teórica.

A integralidade da noção do sujeito individual no âmbito das representações sociais ainda se caracteriza um desafio, uma lacuna, mas pode representar uma possibilidade de distanciar da entonação cognitivista que muitos estudos têm dado as representações sociais. Uma vez que o termo representação social continua influenciado pelo cognitivismo individual, mesmo diante dos esforços empreendidos por Jodelet (2005), revelam-se tendências mecanicistas e computacionais, seguindo o princípio determinista na relação mente, cérebro e comportamento, como alega Marková (2006).

Embora em alguns trabalhos, o retorno ao sujeito individual tenha sido assinalado por Jodelet (2009, 2017), ela aponta González Rey como uma referência nos estudos do sujeito e da subjetividade. Banchs (1996) também faz alusão ao autor, quando verifica a ausência de desenvolvimentos teóricos em termos do papel que a subjetividade e seus aspectos fundamentais tais como necessidades, motivações, emoções, afetos, impulsos inconscientes ou conteúdo reprimido, desempenham na construção das representações sociais.

\section{BRASÍLIA, 22 a 25 DE OUTUBRO DE 2019 CENTRO UNIVERSITÁRIO DE BRASÍLIA - UNICEUB}




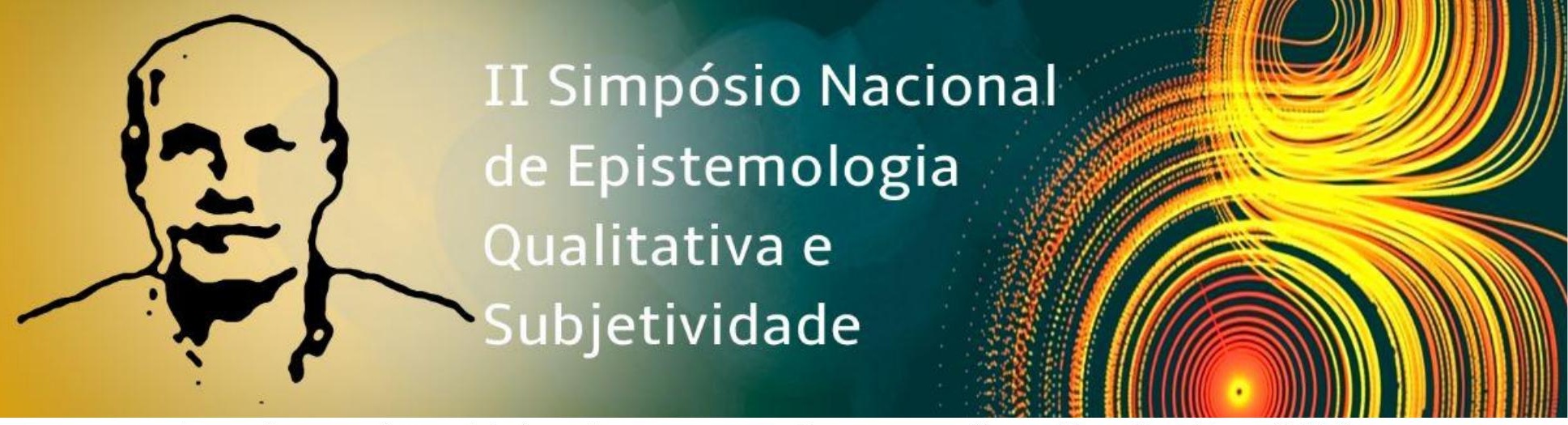

Assumir o caráter subjetivo das representações, como afirma González Rey (2003), reafirma o compromisso com a realidade social, todavia com uma qualidade distinta, como uma realidade que se expressa nas representações sociais de maneira subjetiva e não como reflexo do representado. Evidenciar o sujeito e sua subjetividade no cerne das representações sociais subentende-se enfatizar a relação constitutiva entre o individual e social.

Desta forma, acreditamos que a ênfase à noção do sujeito no escopo da Teoria das Subjetividade possa inspirar novas pesquisas acerca do fenômenos das representações sociais por possibilitar a visibilidade de múltiplas produções simbólico-emocionais dos indivíduos que partilham do mesmo espaço social, como por exemplo a escola.

Neste sentido, entender as representações sociais pelas lentes da definição de subjetividade perseguida por González Rey, significa considerar que essas não fluem sobre os indivíduos como algo externo que os influencia.

Para González Rey (2003) as representações sociais são produções subjetivas, que tem um fundamento do social, mas "não se refere a uma realidade concreta definida em seus atributos objetivos e independentes do indivíduo, mas em uma realidade social, na qual intervêm os processos de subjetivação que a configuram" (GONZÁLEZ REY, 2003, p. 124). Portanto, são subjetivamente configuradas durante as ações contínuas dos indivíduos em um processo nos quais pessoas, ações e contextos são reciprocamente configurados, levando a novas produções de sentidos subjetivos e configurações subjetivas. $O$ sujeito e a subjetividade representam momentos constitutivos do desenvolvimento das representações (GONZÁLEZ REY, 2003).

Corroborando com Jodelet (2005) o autor relata que a forma como a TRS tem sido explorada tem limitado o conceito de representações sociais, afastando-se da ideia seminal de Moscovici. Enfatiza sua crítica aos estudos descritivos estreitos que foram realizados e ainda, a subordinação às regras do método, associando as representações sociais a um grupo de atributos conscientes por um meio de questionários quantificados.

Como já mencionado, Moscovici não desenvolveu uma metodologia própria para os estudos das representações sociais e demonstrou resistência em apresentar um conceito imperativo acerca das mesmas, julgando que tal feito poderia resultar em uma limitação de seu alcance conceitual. 


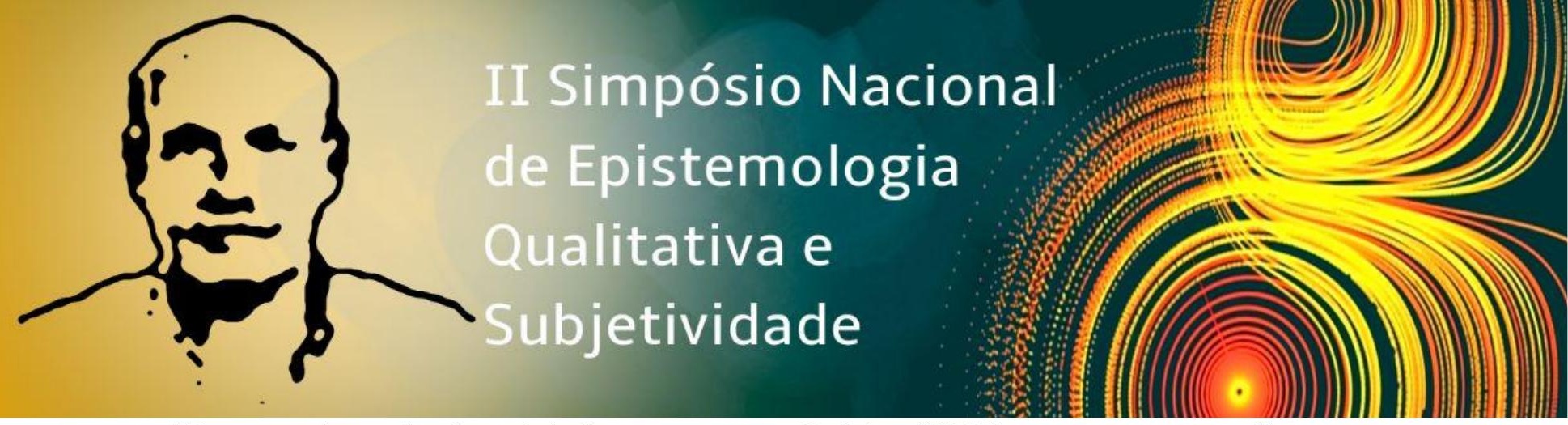

"Retornar à noção de sujeito" como aponta Jodelet (2017), em nosso entendimento, seria trazer para o centro da teoria toda a complexidade que constitui o humano, suas contradições, ambiguidades, polissemias, tal como tem sido buscado na Teoria da Subjetividade.

Corroborando com a visão de González Rey (2008), acreditamos que uma metodologia diferenciada, que não limite o conceito de representações sociais a seus aspectos cognitivos ou que esteja estritamente relacionada a um grupo de atributos definidos por questionários quantificados, poderia contribuir para o entendimento de sua gênese, contextos, dinâmicas e relações.

O conjunto metodológico construtivo-interpretativo decorrente da Epistemologia qualitativa, que visa avançar na compreensão do complexo processo do desenvolvimento da subjetividade, pode se configurar como uma alternativa no alcance do processo de subjetivação na produção das representações sociais, permitindo a expressão das complexas redes de sentido que estão na base das representações. (GONZÁLEZ REY, 2003).

Compreender as representações sociais como parte de subjetividade social requer uma metodologia uma produção construtiva interpretativa que vá além de um primeiro olhar sobre as informações. A tríade Teoria da Subjetividade, Epistemologia Qualitativa e Metodologia Construtiva-interpretativa que balizam esse constructo, alinhados aos princípios que a delineiam podem subsidiar a compreender a participação efetiva dos indivíduos na produção de representações sociais, que se expressam em ações e comportamentos decorrentes dessa configuração subjetiva organizada singularmente.

Do exposto, procuramos apontar algumas implicações no campo das representações sociais a partir da óptica de grandes teóricos que estão pensando os desafios das pesquisas em representações sociais. Entre esses desafios, o desenvolvimento de construções teóricas que permitam resgatar o sujeito, o que implica conceber sua subjetividade, integrando processos simbólicos e emocionais à construção teórica das Representações Sociais, por esses processos caracterizarem as ações do sujeito dentro das redes sociais que definem a vida humana.

Palavras chave: Teoria da Subjetividade, Representações Sociais. Epistemologia Qualitativa 


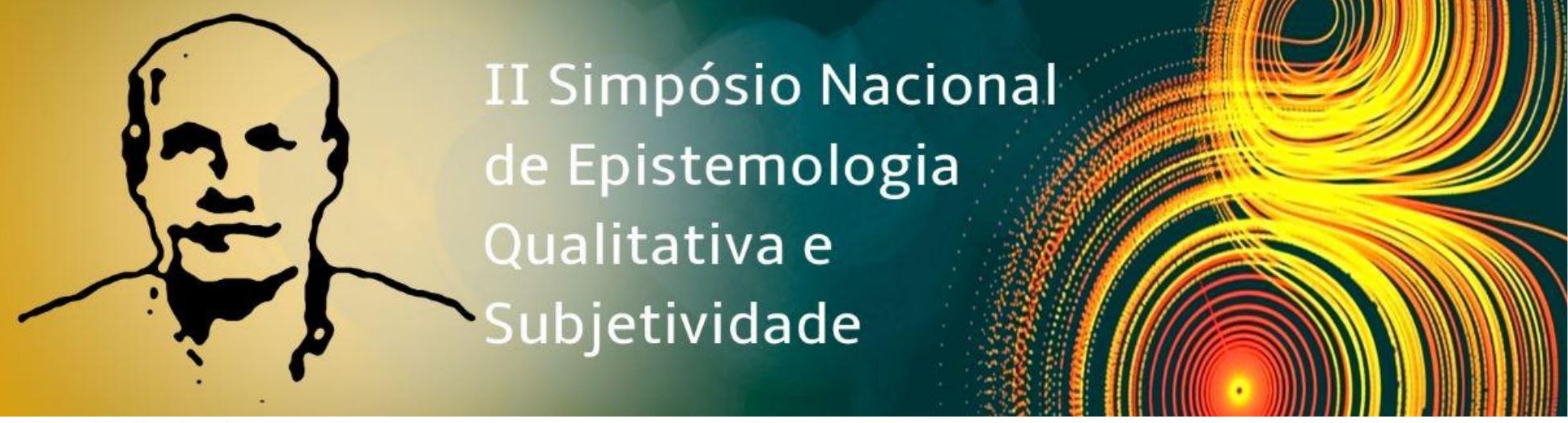

\section{Referências}

ABRIC, Jean Claude. A abordagem estrutural das representações sociais. In: MOREIRA, Antônia Silva Paredes; OLIVEIRA; OLIVEIRA, Denize Cristina. Estudos interdisciplinares de representação social. Goiânia: Ed. AB, 1998

BANCHS, María Auxiliadora. Representaciones Sociales y subjetividad. In: Por uma epistemologia da subjetividade: um debate entre a teoria sócio histórica e a Teoria das Representações Sociais. Odair Furtado, Fernando L. González Rey (Orgs.). São Paulo: Casa do Psicólogo, 2002.

.El papel de la emoción en la construcción de representaciones sociales: invitación para una reflexión teórica. Textes sur les représentations sociales: espace de discussion, v. 5, n. 2, pp. 113125. 1996.

GONÇALVES, Helenice Maia. Subjetividade e Representações Sociais: Estado da Arte da Produção Nacional 2000-2010. Estágio Pós-Doutoral. Disponível em: $<$ https://www.fcc.org.br/fcc/images/pesquisa/estagios/projetos/HeleniceMGonalves.pdf $>$. Acesso em: 18 jun. 2017

GONZÁLEZ REY, Fernando Luis. A new path for the discussion of Social Representations: advancing the topic of subjectivity from a cultural-historical standpoint. 2015 Disponível em: <https://mail.google.com/mail/u/0/\#search/gonz\%C3\%A1lez+rey/14d81b0e528a476b?projector=1>. Acesso em: 20 fev. 2018

.Sujeito que aprende: Diálogos entre a Psicanálise e o Enfoque Histórico-Cultural. In: Albertina Mitjáns, Patricia Álvarez (Org.). Brasília: Liber Livro, 2014

- O social como produção subjetiva: superando a dicotomia indivíduosociedade numa perspectiva cultural- histórica. Estudos Contemporâneos da Subjetividade - ECOS. Rio de Janeiro, v. 2 n. 2 . p. 167 - 185, 2012b. Disponível em: <http://www.periodicoshumanas.uff.br/ecos/issue/view/188/showToc> Acesso em: 21 jun. 2017.

Subjetividad social, sujeto representaciones sociales. Diversitas. V. 4 N. 2. 2008. Disponível em:<http://revistas.usta.edu.co/index.php/diversitas/article/view/181/282> Acesso em: 20 jun. 2017.

JODELET, Denise. Representações Sociais e mundos de vida. Denise Jodelet: Tradutora, Lilian Ulup. _ Paris: Éditions des archives contemporaines; São Paulo: Fundação Carlos Chagas; Curitiba: PUCPRess, 2017.

Vozes, 2005.

Loucuras e representações sociais. Tradução Lucy Magalhães. - Petropolis, RJ: 
